
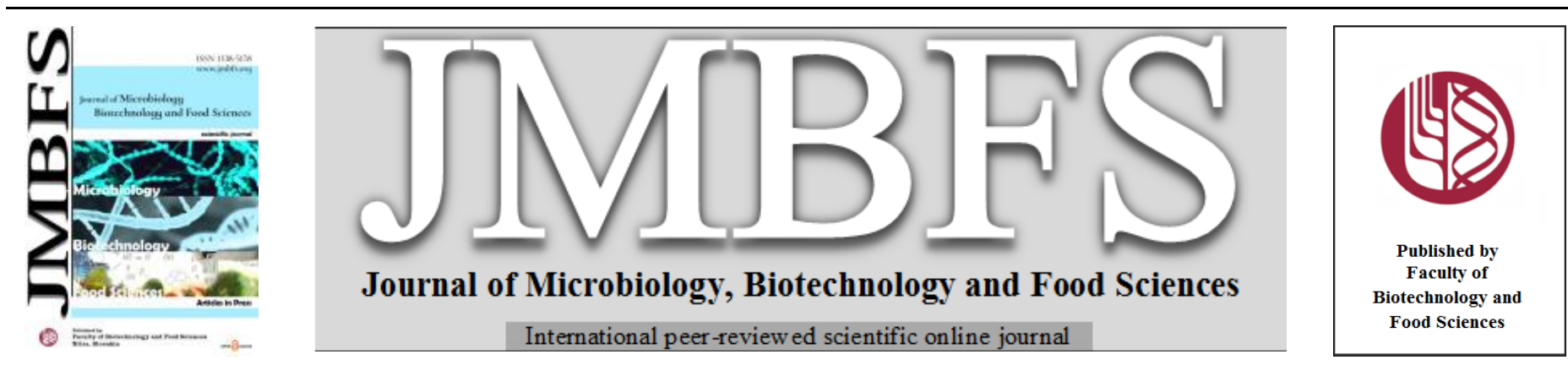

\title{
BACTERIAL INHIBITORY EFFECT OF ALGERIAN POMEGRANATE (Punica Granatum L.) EXTRACTS (PEEL, JUICE, AND SEED) AGAINST MULTIDRUG RESISTANT BACTERIA
}

\author{
Aicha Debib ${ }^{1}$, Soumaya Menadi ${ }^{2}$, Fatima Sahnouni ${ }^{3}$, Mohamed Nadjib Boukhatem ${ }^{2}$, Celia Ouahchia ${ }^{2}$ and Amel Kaced $^{4}$
}

Address(es): ${ }^{1}$ Laboratory Management and Valorization of Agricultura 1 \& Aquatic Ecosystems (LMVAAE), Morsli Abdellah Tipaza University Center, Ouade Merzouk 42000, Algeria.

${ }^{2}$ Department of Biology, Faculty of Life and Natural Sciences, University Blida 1, BP 270 road soumaa, Blida 9000, Algeria.

${ }^{3}$ Faculty of Natural Sciences and Life, University of Mascara, Algeria.

${ }^{4}$ Center of Scientific and Technical Research in Physico-Chemical Analysis (CRAPC), Algeria.

*Corresponding author: a debib@yahoo.fr

https://doi.org/10.55251/jmbfs.4622

\section{ARTICLE INFO}

Received 26. 3. 2021

Revised 10. 9. 2021

Accepted 14. 9. 2021

Published 1. 2. 2022

Regular article

open 2 access

\begin{abstract}
Punica granatum L. (pomegranate) is known popularly by its nutritional values and healthy benefits. The current study is aimed the evaluation of antibacterial effects of Punica granatum fruit extracts that cultivated in Algeria against environmental and clinical isolates of $\beta$-lactamase producing methicillin resistant Staphylococcus aureus (MRSA) and extended-spectrum beta-lactamase ESBL-producing Enterobacteriaceae by using agar diffusion methods and minimum inhibitory concentration (MIC)-determination. Moreover, the extracts were investigated for their phenolic content by the Folin-Ciocalteu method. The quantitative assays of total polyphenols revealed a richness of the different pomegranate extract in polyphenols, peel and seed ethanol extracts contain the highest values (880.06 $\pm 11.2 \mathrm{mg} \mathrm{GAE} / 100 \mathrm{~g}$ and $1160.1 \pm 45.20 \mathrm{mg} \mathrm{GAE} / 100 \mathrm{~g}$, respectively). Flavonoid contents were high in both of acetone, ethanol extracts of peel, followed by ethanol, and acetone extracts of juice. According to the disc diffusion data, all phenolic extracts had a bacterial inhibitory effect against all extended-spectrum beta-lactamase ESBL-producing Enterobacteriaceae with a strong inhibitor with MIC $512 \mathrm{~g} / \mathrm{mL}$ strength. The pericarp extract is particularly effective against Escherichia coli, Citrobacter freundii, and Klebseilla pneumoniae. However, the extract Punica granatum (pericarp and juice) revealed broad-spectrum antibacterial activity with an inhibitory diameter zone size of $110.9 \mathrm{~mm}$ to $291.12 \mathrm{~mm}$ against $\beta$-lactamase generating methicillin resistant Staphylococcus aureus (MRSA) species. These results were similar in both of agar diffusion and MIC methods. From the above study, it can be concluded that Algerian pomegranate extracts possess remarkable antibacterial activity. This result could be related to the presence of bioactive metabolites in this fruit. Therefore, intensive future studies should be performed to characterize the antibacterial components that are behind for this biological property.
\end{abstract}

Keywords: Punica granatum, phenolic compounds, flavonoids, SARM, ESBL, antibacterial activity

\section{INTRODUCTION}

For a long time, antibiotics have been considering as marvelous medications, but their efficacy has been severely hampered by a variety of resistance mechanisms. Antibiotic-resistant microorganisms are becoming more common, posing a serious health risk. Despite the fact that there are almost no new antibacterial medications under development. According to the World Health Organization's 2014 report on global surveillance of antimicrobial resistance, antibiotic resistance is no longer a prediction for the coming years; it is currently happening now, all over the world, and is compromising the capacity to cure serious illnesses in the society and health centers (Aslam et al., 2018). Each year, at leas 25000 individuals in Europe and 23000 in the United States die from infections caused by antibiotic-resistant bacteria (Nathan and Cars, 2014). MethicillinResistant Staphylococcus aureus (MRSA) and Extended-Spectrum $\beta$-Lactamase ESBL-Producing Enterobacteriaceae present special difficulties. Bacteria have the genetic capacity to transfer and develop resistance towards drug generally. Resistance to penicillin and other $\beta$-lactam antibiotics is caused by one of four main processes: antibiotic disintegration by $\beta$-lactamase, alteration of target penicillin Binding Protein (PBPs), reduced drug entry to target PBPs, and efflux. The most prevalent resistance mechanism is $\beta$-lactamase production (Rawat and Nair, 2010; Van den Honert et al., 2021).

The first $\beta$-lactamase with an expanded spectrum was discovered in Germany in the mid-1980s (Kliebe $\boldsymbol{e t}$ al., 1985; Bush, 2018). The ESBL problem originated in west Europe, most likely because antibiotics were initially utilized in therapeutic settings. There are now approximately $610 \beta$-lactamases on the market (Bush and Jacoby, 2010). The enormous range of enzymes makes detecting ESBL-producing bacteria difficult. Different resistance phenotypes emerge based on the amount of enzyme or on which enzymes are present. The spread of ESBL-producing E. coli and $K$. pneumoniae presents a microbiological danger equivalent to MRSA. Although, MRSA has received a lot of attention in the recent decade since it is a major source of hospital transmitted (nosocomial) infections (Sisirak et al., 2010; Foster, 2017). S. aureus has gained resistance to $\beta$-lactam drugs due to the synthesis of chromosomal or plasmid-mediated $\beta$ lactamases or penicillin binding proteins PBPs (Da Costa et al., 2018). As a result, there is a clear need for a fast method of discovering and developing novel antibacterial chemicals. A nutritional strategy might be a viable way to solve this issue.

Almost 25 centuries ago, Hippocrates, the Father of Medicine, stated, "Let food be thy medicine and let medicine be thy food" (Witkamp and van Norren, 2018). To back up this claim, there is currently a lot of interest in functional food and nutraceuticals, which are recognized to play an important role in preventive medicine. Numerous scientific studies have demonstrated the health benefits of a variety of fruits, vegetables, aromatic herbs, medicinal plants and spices (Ray and Bala, 2019). According to in vitro and clinical research, consuming foods high in phenolic compounds may considerably suppress or delay the development rate of a variety of microorganisms (Debib et al., 2014; Duda-Chodak et al., 2015; Makarewicz et al., 2021).

Punica granatum Linn. (Punicaceae) has long been valued for its culinary and medicinal properties (Guerrero-Solano et al., 2020). The fruit is consumed fresh or juiced, and it is used in the food sector to make jellies and syrups (grenadine). Fruit peel has been used as an astringent, stimulant, and natural color in Algerian folk medicine, and it is also suggested for the treatment of dysentery, gastroenteritis, stomach ulcer, bleeding problems, gum irritation, and certain infections (Guerrero-Solano et al., 2020).

Although many reports on the antimicrobial activity of pomegranate exist in the literature, few of them evaluated the antibacterial activity against $\beta$-lactamase 
producing MRSA and ESBL-producing Enterobacteriaceae. This study describes the antibacterial efficacy of Algerian pomegranate variety (juice, peel, and seed) and their phenolic compounds against these multidrug resistant microorganisms.

\section{MATERIELS AND METHODS}

\section{Samples Collection}

$10 \mathrm{Kg}$ of Algerian pomegranate variety namely "Doux de Kolea" collected from local market in Kolea (Tipaza) located in the center of Algeria was confirmed by ITAF (Technical Institute for Fruit Trees) experts. The fruit was washed with tap water followed by washing with distilled water. After opening the fruit, the peel, juice, and seed were separated out

\section{Extracts preparations}

\section{Pomegranate juice and seed extracts preparation}

The vesicle of pomegranate was separated manual1y by removing fruits crusts, then it was rived by an electric blender with very high speed for 5-10 sec. then the mixture was centrifuged for $10 \mathrm{~min}$ at $1400 \mathrm{rpm}$. The liquid phase was separated as the juice and the clot calculated as seeds part. Then 10 grams of both of parts were extracted three times by $100 \mathrm{~mL}$ of each of $(100 \%$ petroleum ether $80 \%$ ethanol and $60 \%$ acetone containing 1\% 2,6-di-tert-butyl-4-methylphenol) in an ultrasonic bath, and filtered by Whatman No.1 filter paper; The solvents were evaporated using a rotary evaporator at $40{ }^{\circ} \mathrm{C}$ to obtain crude three dried extracts of the two parts (juice, seeds). The dried mater from the three extracts were stored at $-20{ }^{\circ} \mathrm{C}$ while waiting for using in the experiments.

\section{Pomegranate peel extracts preparation}

The skins of pomegranate that peeled in the last step were sliced to small pieces and sun-dried up to complete dryness for 10 days. Then it powdered in a mortar and pestle. A quantity of 10 grams of peel powder was extracted (by the same three solvents as above), dried and stored in the same manner.

\section{Detection of phytochemical contents}

The three extracts (ethanol, acetone and petroleum ether) of the three parts (juice, seeds and peels) of Algerian pomegranate, were examined for the secondary metabolites (Tannins, Flavonoids, Alkaloids, Glycosides, Saponins, Coumarins) by chemical and thin-layer chromatography methods that described by Evans (2009) and Paterson (1999).

\section{Total Phenolic Content}

Total polyphenol content of all extracts of the three parts of pomegranate (juice, seeds and peels) were measured by mixing them with Folin-Ciocalteu reagent the development color of reaction mixture were recorded by reading the absorbance at $765 \mathrm{~nm}$ against blank. The absorbance of each sample was compared to a standard response curve of gallic acid $(0,12.5,25,50,100$, and 200 $\mathrm{mg} / \mathrm{mL}$ ) to estimate total phenolic content and concentrations were expressed as $\mathrm{mg}$ gallic acid equivalents (GAE) per $100 \mathrm{~g}$ dry matter (Singleton et al., 1999; Debib and Boukhatem, 2017). The tests were carried out in triplicates for each extracts.

\section{Total Flavonoids Content}

The quantity of flavonoids of all extracts was valued by $\mathrm{AlCl}_{3}$ spectrophotometric method (Sahnouni et al., 2021). Briefly, an aliquot of $1 \mathrm{~mL}$ of each sample or standard solution was added individually to equal volumes of solution of $2 \%$ $\mathrm{AlCl}_{3}, 6 \mathrm{H}_{2} \mathrm{O}$, mixed evenly and allowed to stand at room temperature for $30 \mathrm{~min}$. The absorbance was then read at $415 \mathrm{~nm}$. The quantity of total flavonoids was expressed as $\mathrm{mg}$ of catechin equivalents $(\mathrm{CE})$ per $100 \mathrm{~g}$ dry matter.

\section{Microorganisms Collection}

The microorganisms used are environmental and clinical pathogenic bacteria strains. These strains were isolated from patients whom hospitalized in the Hospital Center of Kolea (Tipaza) and Yessad Khaled hospital (Mascara, situated in the north east of Algeria). Bacterial strains and their origins summarized in Table 1.

\section{Microorganisms identification}

All isolates were presumptively identified by primary phenotypic identification methods based on colony morphology, catalase, coagulase Pastorex Staph plus agglutination test and Gram staining. The API 20E system (bioMerieux, France) was used for identification of Enterobacteriaceae and the API STAPH ID 20 (bioMérieux, france) system for identification of Staphylococcus.

\section{Confirmation of identification by MALDI-TOF mass spectrometry method}

The matrix-assisted laser desorption/ionization-time of flight (MALDI-TOF) mass spectrometer is one of the most widely used mass spectrometers in biology due to its fast and accurate identification of genus and species of a wide variety of Gram-negative and Gram-positive bacteria. In this study, we confirmed the identification of the bacterial strains used by this rapid method. A colony was "picked" from a pure culture plate incubated at $37^{\circ} \mathrm{C}$ for $24 \mathrm{~h}$ to a "spot" on a MALDI-TOF-MS target plate Microflex LT BIOTYPER (BRUKER)® (Bruker Daltonics, Germany). The addition of $1 \mu \mathrm{L}$ of matrix solution $(10 \mathrm{mg} / \mathrm{mL} \alpha-$ cyano-4-hydroxycinnamic acid in 50\% acetonitrile and $2.5 \%$ trifluoroacetic acid) to the MALDI plate was used to improve the quality of the generated mass spectrum. After drying, the target plate is placed in the mass spectrometer's ionization chamber. All spectra were compared with reference spectra of the BDAL database and with main spectrum profiles created.

\section{Antibiotic Sensitivity Test}

The Antibiotic weakness of the ESBL producing bacteria against antibiotics was detected by different antibiotics namely Ampicillin (AM-10), Amoxicillin (AX25), Cefazolin (CZ-30), Amoxicillin-clavulanic acid (AMC-30), Aztreonam (ATM-30) Cefotaxime (CTX-30), Cefixim (CFM-30), Cephalexin (CL-30), Ceftazidim (CAZ-30), Ticarcillin (TIC-75), Imipenem (IMP-10), Vancomycin (VAN-5), Cefoxitin (FOX) (Pasteur institute, France). Antibiotic sensitivity tests were carried out using Mueller Hinton Agar medium by disc diffusion method according that described previously by The Clinical \& Laboratory Standards Institute (CLSI) (CLSI, 2017)

\section{Tests for $\beta$-Lactamase production}

All of bacterial strains of the experiment were screened for their $\beta$-lactamase production ability using the following tests:

\section{Double-disc synergy test}

A discs containing a concentration of $30 \mu \mathrm{g}$ of third generation Cephalosporin, Ceftazidime or Cefotaxime, and a disc of Amoxicillin-clavulanic acid $(20 \mu \mathrm{g}$ amoxicillin $/ 10 \mu \mathrm{g}$ clavulanic acid) were placed $20 \mathrm{~mm}$ apart on Mueller Hinton agar plates on which $0.5 \mathrm{McFarland}$ of test organism was diffused (Titilawo and Okoh, 2015).

\section{Phenotypic confirmation test}

Disc tests were achieved for phenotypic confirmation of the presence of ESBLs by using cefotaxime $(30 \mu \mathrm{g})$ or ceftazidime $(30 \mu \mathrm{g})$ discs with or without clavulanate $(10 \mu \mathrm{g})$ according to CLSI recommendations. The presence of ESBLproducing bacteria distinguished by the zone diameter of cephalosporin/clavulanate disc which are larger than the zone of cephalosporin disc by was $5 \mathrm{~mm}$ (CLSI, 2017). Klebsiella pneumoniae 700603 was used as a control strain for a positive ESBL production and Escherichia coli 25922 was used as a negative control for the ESBL production.

Table 1 Origin of Staphylococcus aureus and Enterobacteriaceae isolates.

\begin{tabular}{lccc}
\hline Gram type & Strains & Origin \\
\cline { 2 - 4 } Gram + & Staphylococcus aureus & MSSA(WEK1) & Wound \\
(09 strains) & (MSSA) & MSSA(WEK2) & exudates \\
& (05 strains) & MSSA(WEK3) & Hospital Center \\
& & MSSA(WEK4) & of Kolea \\
& MSSA(WEK5) & \\
& Staphylococcus aureus & MRSA(WEK1) & \\
& MRSA(WEK2) & \\
Gram - & MRSA(WEK3) & \\
strains & Leclercia adecarboxylata $)$ & ESBL & \\
(11 strains) & Citrobacter diversus & ESBL & Mascara \\
& Proteus vulgaris & ESBL & wastewater \\
& Citrobacter freundii & ESBL & \\
& Escherichia coli $($ E.c 1) & ESBL & \\
& Providencia stuartii & ESBL & \\
& Klebseilla pneumoniae & ESBL & \\
& Escherichia coli ( .c. 2$)$ & ESBL Urine & \\
& Kleibseilla pneumoniae & ESBL Urine & Mascara \\
& Proteus mirabilis & ESBL Urine & Yessad \\
& Shigella flexneri & ESBL Stool & Khaled hospital \\
& specimen & \\
\hline MSSA: Methicillin-susceptible Staphylococcus aureus, MRSA : Methicillin-
\end{tabular}

resistant Staphylococcus aureus. ESBL: Extended-Spectrum Beta-Lactamase 
Iodometric Method was realized as earlier described by Agu et al., (2020) Briefly, $0.5 \mathrm{~mL}$ of Penicillin solution was dispensed into test tubes that contained the test bacteria and adjusted using normal saline to $0.5 \mathrm{McF}$ arland standard After one hour at room temperature, two drops of starch indicator was added to the suspension, followed by one drop of iodine reagent.

\section{Evaluation of antibacterial effects of pomegranate extracts}

The effects of Algerian pomegranate fruit extracts was determined by disc diffusion method on Mueller-Hinton agar medium (Pasteur institute, Algiers, Algeria) according to the method that described by CLSI (2017). The extracts were dissolved in dimethyl sulfoxide (DMSO) or distilled water. Petri plates were prepared with $20 \mathrm{~mL}$ of sterile Mueller Hinton agar (Sigma, Paris, France) surface inoculate by suspension of cell $(200 \mathrm{~mL})$ adjusted by McFarland 0.5 method $\left(10^{6} \mathrm{CFU} / \mathrm{mL}\right)$. Sterile filter paper discs of $9 \mathrm{~mm}$ diameter were impregnated with $20 \mu \mathrm{L}$ of the extract solution and putted in the inoculated Petri dishes. The plates were incubated at $37^{\circ} \mathrm{C}$ for $24 \mathrm{~h}$. Control samples were carried out using paper discs soaked in $20 \mu \mathrm{L}$ of the solvents utilized (DMSO or water). The zone of growth inhibition around the discs was measured to assess antibacterial effect. The inhibitory areas were then determined by measuring using Vernier calipers. To reduce test mistake, all experiments were run three times. High antimicrobial property was defined as an inhibitory zone of $14 \mathrm{~mm}$ or more (including the diameter of the disc).
Antimicrobial activity of the different extracts of pomegranate fruit parts was achieved using Minimum Inhibitory Concentration (MIC) method by microdilution assays in 96-well plates, which described by Debib et al., (2014).

\section{Statistical Analysis}

All the results of this study were analyzed by the statistical software (Statistica) Results were expressed as mean of three replicates \pm standard error of means (SEM). Differences between means were evaluated by one-way ANOVA followed by Tukey's post-hoc multiple comparison test $(p$ values $<0.05$ were considered significant).

\section{RESULTS}

\section{Phytochemical contents of pomegranate fruit extracts}

The results of preliminary phytochemical screening of $P$. granatum fruit extracts are illustrated in Table 2. The results showed presence of tannins, flavonoids, and glycosides in high quantities and low amounts of alkaloids in both of ethanol and acetone extracts of the peel, while in petroleum ether extract of peel only glycosides and flavonoids were appeared in low quantities, but there are neither saponins nor coumarins were found in all of peel extracts.

Table 2 Preliminary phytochemical screening of the investigated extracts of $P$. granatum

\begin{tabular}{lcccccccccc}
\hline & \multicolumn{3}{c}{ Peel extract } & \multicolumn{3}{c}{ Juice extract } & \multicolumn{3}{c}{ Seed extract } \\
\cline { 2 - 10 } Tannins & Ethanol & Acetone & Pet. ether & Ethanol & Acetone & Pet. ether & Ethanol & Acetone & Pet. ether \\
\cline { 2 - 10 } & ++ & ++ & - & + & - & - & - & - & - \\
Flavonoids & ++ & ++ & + & + & + & + & - & - & - \\
Alkaloids & + & + & - & - & - & - & - & - & - \\
Glycosides & ++ & ++ & + & + & + & - & - & - & - \\
Saponins & - & - & - & + & - & - & + & - & - \\
Coumarins & - & - & - & - & - & - & - & - & - \\
\hline$+:$ Presence, - :Absence.
\end{tabular}

In juice extracts, flavonoids were found in all of solvents extracts but in small amounts, both of flavonoids and glycosides were detected in ethanol and aceton extracts of juice, whereas tannins and saponins found only in ethanol extract, each of alkaloids and coumarins were not found in both of juice and seed extracts at all. The unique secondary metabolite in seed extracts was saponins.

\section{Total phenolic and flavonoid contents of pomegranate extracts}

\section{Total phenolic contents}

In Fig. 1, the amounts of polyphenols in pomegranate fruit different extracts are explored. The extracts of ethanol were contained the highest polyphenols concentrations, followed by acetone extracts and in the last order petroleum ether extracts.

Ethanol seed extract showed the largest concentration of polyphenols (1160.1 $\pm 45.20 \mathrm{mg}$ GAE$/ 100 \mathrm{~g})$ followed by peel ethanol extract $(880.06 \pm 11.2 \mathrm{mg}$ $\mathrm{GAE} / 100 \mathrm{~g})$ and the juice ethanol polyphenols was the lowest $(690.89 \pm 5.65 \mathrm{mg}$ GAE/100 g). Similar quantities of polyphenols were found in both of peel $(680.44 \pm 23.66 \mathrm{mg} \mathrm{GAE} / 100 \mathrm{~g})$ and seed $(677.56 \pm 10.23 \mathrm{mg}$ GAE/100 g) acetone and petroleum ether extracts while juice acetone $(340.33 \pm 11.11 \mathrm{mg}$ $\mathrm{GAE} / 100 \mathrm{~g})$ and petroleum ether $(90.33 \pm 0.9 \mathrm{mg} \mathrm{GAE} / 100 \mathrm{~g})$ were low in their polyphenols contents. Statistically there were significant differences between polyphenols of the different solvent extracts at level $(p \geq 0.05)$, but the highest significant differences were between both of peel and seed extracts (Fig. 1).

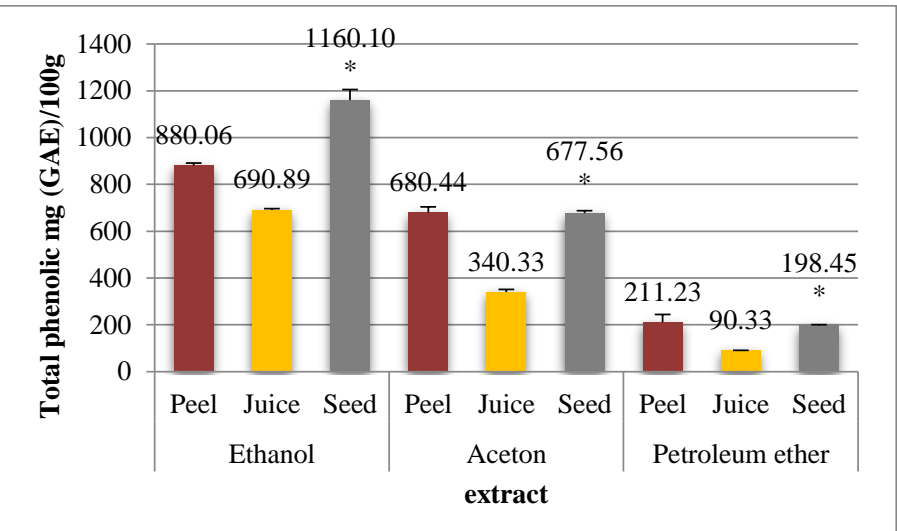

Figure 1 Total phenolic content as gallic acid equivalent (GAE mg/100 g) in Punica granatum extracts $(* p<0.05$. As compared with the Peel extracted by the same solvent).

\section{Total flavonoids contents}

The total flavonoid content of extracts is expressed in terms of catechin equivalent (the standard curve equation: $\mathrm{y}=0.005 \mathrm{x}+0.1478, r^{2}=0.9979$ ). As shown in Fig. 2, the concentration of flavonoids in the different extracts of pomegranate fruit, peel ethanol and acetone extracts were found to contained the large flavonoids values $(77.06 \pm 10.11 \mathrm{mg} \mathrm{CE} / 100 \mathrm{~g}$ and $80.23 \pm 12.23 \mathrm{mg} \mathrm{CE} /$ $100 \mathrm{~g}$ respectively), followed by juice ethanol $(49.89 \pm 3.45 \mathrm{mg} \mathrm{CE} / 100 \mathrm{~g})$ and acetone $(30.33 \pm 0.5 \mathrm{mg} \mathrm{CE} / 100 \mathrm{~g})$ extracts, with significant differences between them in comparing with seed extracts, where all sees extracts were very poor in flavonoids as soon as all of petroleum ether extracts of all parts of pomegranate fruit. 


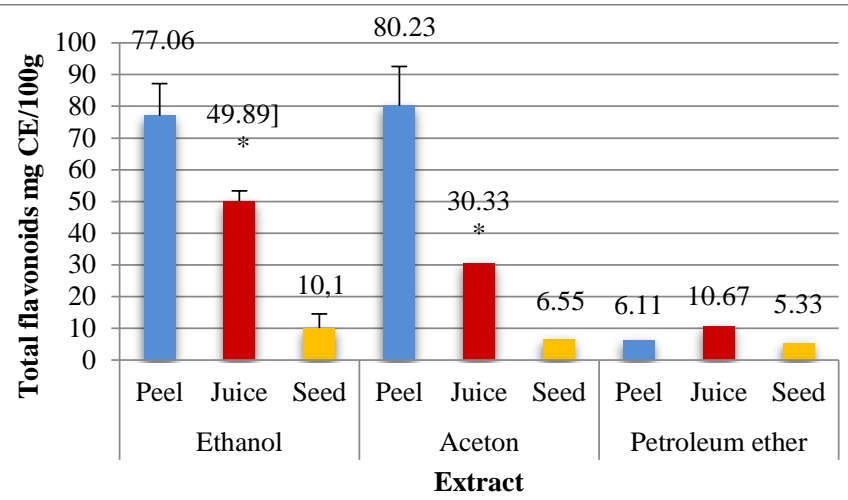

Figure 2 Total flavonoids content as catechin equivalent (mg/100 g) in Punica granatum extracts

$\left({ }^{*} p<0.05\right.$. As compared with the seed extracted by the same solvant)

Antimicrobial activity of Punica granatum Extracts

\section{Antibacterial activity against Staphylococcus aureus strains}

Nine clinical strains of $S$. aureus isolated from wound exudates Hospital Center of Kolea (Tipaza, Algeria) were tested to observe their antimicrobial activity.
From antibiotic resistance results in (Table 3), we can observe that most of the tested strains have developed a specific resistance against antibiotics. However, the results showed that different strains were sensitive toward the extracts obtained in this study.

Table 3 Antibiotic resistance profile of $S$. aureus strains tested by the disk diffusion method

\begin{tabular}{|c|c|c|c|c|}
\hline \multirow{2}{*}{$\begin{array}{l}\text { Strains } \\
\text { Designation }\end{array}$} & \multirow[t]{2}{*}{ Antibiotic resistance Pattern } & \multicolumn{3}{|c|}{$\begin{array}{c}\text { MICs of } \beta \text {-lactam } \\
\text { antibiotics }\end{array}$} \\
\hline & & $\mathrm{P}$ & $\mathrm{OX}$ & FOX \\
\hline MSSA(WEK1) & $\mathrm{P}, \mathrm{E}, \mathrm{TE}, \mathrm{AM}, \mathrm{GEN}$ & 512 & 128 & 256 \\
\hline MSSA(WEK2) & P, AM, FOX, K & 128 & 128 & 32 \\
\hline MSSA(WEK3) & $\mathrm{P}, \mathrm{FOX}, \mathrm{K}, \mathrm{GEN}$ & 128 & 128 & 64 \\
\hline MSSA(WEK4) & $\mathrm{P}, \mathrm{GEN}$ & 256 & 128 & 32 \\
\hline MSSA(WEK5) & P, AM, FOX, K, OFX, GEN & $>512$ & 256 & 256 \\
\hline MRSA(WEK1) & $\begin{array}{c}\mathrm{P}, \mathrm{OX}, \mathrm{AM}, \mathrm{CEP}, \mathrm{CEF}, \mathrm{CET}, \\
\text { P, FOX, E }\end{array}$ & $\mathrm{R}$ & $\mathrm{R}$ & $\mathrm{R}$ \\
\hline MRSA(WEK2) & $\begin{array}{c}\mathrm{P}, \mathrm{OX}, \mathrm{AM}, \mathrm{CEP}, \mathrm{M}, \mathrm{CEF}, \\
\text { CET }\end{array}$ & 256 & $\mathrm{R}$ & 256 \\
\hline MRSA(WEK3) & $\begin{array}{c}\mathrm{P}, \mathrm{OX}, \mathrm{AM}, \mathrm{CEP}, \mathrm{M}, \mathrm{CEF}, \\
\text { CET, FOX }\end{array}$ & 512 & $\mathrm{R}$ & 512 \\
\hline MRSA(WEK4) & $\mathrm{P}, \mathrm{OX}, \mathrm{AM} ; \mathrm{FOX}, \mathrm{M}, \mathrm{TET}$ & $>512$ & $\mathrm{R}$ & $>512$ \\
\hline
\end{tabular}

MRSA = Methicillin-resistant Staphylococcus aureus ; MSSA = Methicillinsusceptible Staphylococcus Aureus ; R ; resistant ; FOX = cefoxitin ; OX = Oxacillin ; P : Penicillin.

Table 4 Antimicrobial activity of the crude extracts of $P$. granatum in agar diffusion assay $(* P<0.05$. As compared with the Juice and seed extracted by the same solvent)

\begin{tabular}{|c|c|c|c|c|c|c|c|c|c|}
\hline \multirow[b]{2}{*}{ Strains } & \multicolumn{3}{|c|}{ Ethanol extrcat } & \multicolumn{3}{|c|}{ Aceton extrcat } & \multicolumn{3}{|c|}{ Petroleum ether extrcat } \\
\hline & Peel & Juice & Seed & Peel & Juice & Seed & Peel & Juice & Seed \\
\hline MSSA(WEK1) & $29 \pm 1.12$ & $15 \pm 2.2$ & 12.5 & 28 & $17 \pm 0.5$ & 0 & $12.5 \pm 0.66$ & 0 & 0 \\
\hline MSSA(WEK2) & $28 \pm 1.33$ & 0 & 0 & 23 & $10 \pm 1.5^{*}$ & 0 & $12 \pm 0.66$ & 0 & 0 \\
\hline MSSA(WEK3) & $26 \pm 0.7$ & $11 \pm 0.9$ & $12 \pm 1.11$ & 15 & $20 \pm 2.11$ & 0 & 10 & 0 & 0 \\
\hline MSSA(WEK4) & $20 \pm 0.66^{*}$ & $12 \pm 0.4$ & 0 & 20 & $13 \pm 0.9$ & 0 & $9.5 \pm 0.33$ & 0 & 0 \\
\hline MSSA(WEK5) & $23 \pm 1.11^{*}$ & $11 \pm 1.10$ & 0 & 16 & $14 \pm 0.9$ & 0 & 12 & 0 & 0 \\
\hline MRSA(WEK1) & $23 \pm 0.22$ & 0 & 0 & 22 & $12 \pm 0.11$ & 0 & 13.5 & 0 & 0 \\
\hline MRSA(WEK2) & $24 \pm 1.34 *$ & 12 & 0 & 21 & 0 & 0 & 11 & 0 & 0 \\
\hline MRSA(WEK3) & $25 \pm 0.33$ & 13 & 0 & 18 & $16 \pm 0.5^{*}$ & 0 & 10 & 0 & 0 \\
\hline MRSA(WEK4) & 22 & 12 & 0 & 16 & $13 \pm 0.2$ & 0 & 0 & 0 & 0 \\
\hline
\end{tabular}

MRSA = Methicillin-resistant Staphylococcus aureus $;$ MSSA = Methicillin-susceptible Staphylococcus aureus.

Different portions of Algerian $P$. granatum (peel, juice and seeds) extracts showed significant antibacterial effects against $S$. aureus strains in this experiment. The inhibition zone were recorded to by $9.5 \pm 0.33 \mathrm{~mm}$ as the minimum antimicrobial effects for peel petroleum ether against MSSA(WEK4) strain. While the maximum inhibitor effect $(29 \pm 1.12 \mathrm{~mm})$ was recorded for MSSA (WEK1) isolate. Ethanol and acetone extracts of peel displayed the uppermost activity against $S$. aureus, ethanol and acetone extracts of juice were in the second order, while seeds extracts not recorded antibacterial activity except with tow strains of $S$. aureus strains by ethanol extract. These results were similar in both of agar diffusion and MIC methods in table 5 .

Table 5 MICs values for the investigated extracts of $P$. granatum against S.aureus strains

\begin{tabular}{lccccccccc}
\hline & \multicolumn{3}{c}{ Ethanol extrcat } & \multicolumn{3}{c}{ Aceton extrcat } & \multicolumn{3}{c}{$\begin{array}{c}\text { Petroleum ether } \\
\text { extrcat }\end{array}$} \\
\hline Strains & Peel & Juice & Seed & Peel & Juice & Seed & Peel & Juice & Seed \\
\hline MSSA(WEK1) & 8 & 128 & 64 & 8 & 128 & $\mathrm{R}$ & 256 & $\mathrm{R}$ & $\mathrm{R}$ \\
MSSA(WEK2) & 8 & $\mathrm{R}$ & $\mathrm{R}$ & 8 & 256 & $\mathrm{R}$ & 256 & $\mathrm{R}$ & $\mathrm{R}$ \\
MSSA(WEK3) & 8 & $>512$ & 256 & 128 & 32 & $\mathrm{R}$ & 512 & $\mathrm{R}$ & $\mathrm{R}$ \\
MSSA(WEK4) & 16 & 256 & $\mathrm{R}$ & $>512$ & 256 & $\mathrm{R}$ & 512 & $\mathrm{R}$ & $\mathrm{R}$ \\
MSSA(WEK5) & 8 & 256 & $\mathrm{R}$ & 128 & 128 & $\mathrm{R}$ & 256 & $\mathrm{R}$ & $\mathrm{R}$ \\
MRSA(WEK1) & 8 & $\mathrm{R}$ & $\mathrm{R}$ & 64 & 256 & $\mathrm{R}$ & 256 & $\mathrm{R}$ & $\mathrm{R}$ \\
MRSA(WEK2) & 8 & 128 & $\mathrm{R}$ & 64 & $\mathrm{R}$ & $\mathrm{R}$ & 256 & $\mathrm{R}$ & $\mathrm{R}$ \\
MRSA(WEK3) & 8 & 128 & $\mathrm{R}$ & 64 & 128 & $\mathrm{R}$ & $>512$ & $\mathrm{R}$ & $\mathrm{R}$ \\
MRSA(WEK4) & 16 & 128 & $\mathrm{R}$ & 64 & 128 & $\mathrm{R}$ & $\mathrm{R}$ & $\mathrm{R}$ & $\mathrm{R}$ \\
\hline
\end{tabular}

MRSA = Methicillin-resistant Staphylococcus aureus $;$ MSSA = Methicillinsusceptible Staphylococcus Aureus; R : resistant; MIC: Minimum inhibitory concentration.

\section{ESBL-producing Enterobacteriaceae}

From antibiotic resistance results (Table 6), we can observe that most of the tested strains have developed a particular resistance against several antibiotics (AMX, AMC, CZ, CN, OX, and CAZ). However, we find that different strains are sensitive to the monobactam such as ATM, and some of the third generation antibiotics (CTX and CEF).
Table 6 Antibiotic resistance profile of ESBL-producing Enterobacteriaceae.

\begin{tabular}{|c|c|c|c|c|}
\hline \multirow[t]{2}{*}{ Strains Designation } & \multirow{2}{*}{$\begin{array}{c}\text { Antibiotic resistance } \\
\text { pattern }\end{array}$} & \multicolumn{3}{|c|}{$\begin{array}{l}\text { MICs of } \beta \text {-lactam } \\
\text { antibiotics }\end{array}$} \\
\hline & & CTX & $\mathrm{CEF}$ & ATM \\
\hline $\begin{array}{l}\text { Leclercia } \\
\text { adecarboxylata }\end{array}$ & $\begin{array}{c}\text { AMX, AMC, CZ, CL, OX, } \\
\text { CAZ }\end{array}$ & 512 & 256 & $\mathrm{R}$ \\
\hline Citrobacter diversus & $\begin{array}{c}\mathrm{AMX}, \mathrm{AMC}, \mathrm{CZ}, \mathrm{CN}, \mathrm{OX}, \\
\text { CAZ }\end{array}$ & 256 & 256 & 256 \\
\hline Proteus vulgaris & $\mathrm{AMX}, \mathrm{AMC}, \mathrm{CZ}, \mathrm{OX}, \mathrm{CAZ}$ & $>512$ & 128 & 128 \\
\hline Citrobacter freundii & $\begin{array}{c}\mathrm{AMX}, \mathrm{AMC}, \mathrm{CZ}, \mathrm{CN}, \mathrm{OX} \\
\mathrm{CAZ}\end{array}$ & 512 & 256 & 128 \\
\hline $\begin{array}{l}\text { Escherichia coli (E.c } \\
\text { 1) }\end{array}$ & $\begin{array}{c}\mathrm{AMX}, \mathrm{AMC}, \mathrm{CZ}, \mathrm{CN}, \mathrm{OX}, \\
\mathrm{CAZ}\end{array}$ & 256 & 256 & 256 \\
\hline Providencia stuartii & $\begin{array}{c}\text { AMX, AMC, CZ, CN, OX, } \\
\text { CAZ, ATM }\end{array}$ & 512 & 256 & $\mathrm{R}$ \\
\hline $\begin{array}{l}\text { Klebseilla } \\
\text { pneumoniae }\end{array}$ & $\begin{array}{c}\text { AMX, AMC, CZ, CN, OX, } \\
\text { CAZ, ATM }\end{array}$ & 256 & 128 & $\mathrm{R}$ \\
\hline $\begin{array}{l}\text { Escherichia coli (E.c } \\
\text { 2) }\end{array}$ & $\begin{array}{c}\mathrm{AMX}, \mathrm{AMC}, \mathrm{CZ}, \mathrm{CN}, \mathrm{OX}, \\
\mathrm{CAZ}\end{array}$ & $\mathrm{R}$ & $\mathrm{R}$ & $\mathrm{R}$ \\
\hline Shigella sp.. & $\begin{array}{c}\text { AMX, AMC, CZ, CN, OX, } \\
\text { CAZ, ATM }\end{array}$ & $\mathrm{R}$ & $\mathrm{R}$ & $\mathrm{R}$ \\
\hline
\end{tabular}

MIC: Minimum inhibitory concentration; CTX: Cefotaxime; CEF: cephalothin; ATM: Aztreonam; R: Resistant.

Antibacterial effects of all extracts against ESBL-producing Enterobacteriaceae (Table 7) showed that bacterial inhibitor activity were recorded by peel ethanol and acetone extracts $(29 \mathrm{~mm})$ against Proteus vulgaris as the highest value whereas the lowest value $(8 \mathrm{~mm})$ was reported for seed ethanol extract against Proteus vulgaris and for seed acetone extract against Citrobacter diversus using agar diffusion method. MICs values of Algerian pomegranate against ESBLproducing Enterobacteriaceae were ranged from $8 \mu \mathrm{g} / \mathrm{mL}$ for seed ethanol and peel ethanol extract against each of Citrobacter diversus, Citrobacter freundii and Escherichia coli (E.c 1) and for peel acetone extracts against Citrobacter freundii and Escherichia coli (E.c 1) the highest value was $512 \mu \mathrm{g} / \mathrm{mL}$ or more for ethanol extract of seed against Escherichia coli (E.c 1) and for acetone seed 


\begin{tabular}{|c|c|c|c|c|c|c|c|c|c|}
\hline \multirow[b]{2}{*}{ Strains } & \multicolumn{3}{|c|}{ Ethanol extrcat } & \multicolumn{3}{|c|}{ Aceton extrcat } & \multicolumn{3}{|c|}{ Petroleum ether extrcat } \\
\hline & Peel & Juice & Seed & Peel & Juice & Seed & Peel & Juice & Seed \\
\hline Leclercia adecarboxylata & $26 \pm 2.03$ & $16 \pm 0.11$ & 12 & $22 \pm 0.71$ & 15 & 9 & $16 \pm 1.92$ & 14 & 10 \\
\hline Citrobacter diversus & $25 \pm 0.15$ & $25 \pm 2.23$ & 9 & $26 \pm 1.26$ & 21 & 8 & $21 \pm 2.02$ & 15 & 14 \\
\hline Proteus vulgaris & $28 \pm 1.07$ & 17 & 13 & $29 \pm 3.12$ & 17 & 12 & 14 & 16 & 18 \\
\hline Citrobacter freundii & 24 & $20 \pm 0.91$ & 15 & $27 \pm 0.92$ & 19 & 11 & 12 & 15 & 14 \\
\hline Escherichia coli (E.c 1) & $26 \pm 3.02$ & 19 & 8 & 28 & 28 & 9 & 12 & 17 & 12 \\
\hline Providencia stuartii & 11 & $20 \pm 3.11$ & 12 & 25 & 27 & 11 & 14 & 10 & 12 \\
\hline Klebseilla pneuтoniae & $13 \pm 0.09$ & 18 & 14 & 20 & 23 & 10 & $15 \pm 0.98$ & 13 & 9 \\
\hline Escherichia coli (E.c 2) & 18 & 19 & 12 & $28 \pm 0.77$ & 16 & 9 & 14 & 14 & 10 \\
\hline Shigella sp. & 18 & $25 \pm 2.21$ & 14 & $26 \pm 0.66$ & 27 & 13 & 16 & 14 & 14 \\
\hline
\end{tabular}

Table 8 MICs values in $\mu \mathrm{g} / \mathrm{mL}$ for the investigated extracts of $P$. granatum against ESBLproducing Enterobacteriaceae.

\begin{tabular}{lccccccccc}
\hline & \multicolumn{3}{c}{ Ethanol extrcat } & \multicolumn{3}{c}{ Aceton extrcat } & \multicolumn{3}{c}{ Petroleum ether extrcat } \\
\cline { 2 - 10 } Strains & Peel & Juice & Seed & Peel & Juice & Seed & Peel & Juice & Seed \\
\hline Leclercia adecarboxylata & 16 & 128 & 256 & 32 & 128 & 256 & 128 & 128 & 256 \\
Citrobacter diversus & 16 & 32 & 256 & 32 & 256 & 256 & 256 & 128 & 256 \\
Proteus vulgaris & 8 & 128 & 256 & 16 & 128 & 256 & 128 & 128 & 32 \\
Citrobacter freundii & 8 & 64 & 128 & 16 & 128 & 256 & 256 & 128 & 128 \\
Escherichia coli $($ E.c 1) & 8 & 64 & $>512$ & 8 & 16 & 512 & 256 & 64 & 256 \\
Providencia stuartii & 256 & 64 & 256 & 8 & 32 & 256 & 128 & 256 & 256 \\
Klebseilla pneumoniae & 256 & 128 & 256 & 128 & 16 & 512 & 128 & 128 & 512 \\
Escherichia coli $($ E.c 2) & 128 & 128 & 256 & 8 & 128 & 512 & 256 & 128 & 512 \\
\hline
\end{tabular}

\section{DISCUSSION}

In recent decades, a large number of studies have demonstrated that the consumption of plant-based foods, such as fruits, vegetables and whole grains, can help prevent the development of many diseases (Witkamp and Van Norren, 2018). The health benefits of these plant-based foods and natural health products are generally attributed to the phytochemicals present in them, especially phenolic compounds. This paper is a modest contribution to the ongoing discussions about the antibacterial potential of three different extracts of Algerian $P$. granatum against environmental and clinical isolates of $\beta$-lactamase producing MRSA and ESBL-producing Enterobacteriaceae.

From the phytochemical analysis, peel extract of fruit was found to have more constituents compared to juice and seeds extracts. Similar findings were also reported by other studies (Amararatne et al., 2012; Sh. Ergasheva et al., 2019). Other researchers have analyzed the phytochemical constituents in pomegranates from various locally available cultivars, and found the polyphenolics to be more abundant in the peels in comparison to other parts of the fruit (Al-Zoreky, 2009; Gözlekçi et al., 2011; Benguiar et al., 2020). The ethanol and acetone remain good extraction solvents of secondary metabolites. Furthermore, the phenolic compounds solubility is affected by the solvent polarity used which makes it difficult to establish all plant phenolic compounds extracting process (Thongson et al., 2004; Guessaibia et al., 2019). It was interesting to note that polyphenols are hydrophilic phytochemicals and hydrophilic solvents are more effective agents for the extraction. According to the literature, it has been reported that the ultrasonic extraction generally increases the efficiency extraction (Sharayei $\boldsymbol{e}$ al., 2019). Thongson et al., (2004) reported that ultrasonic extraction took only 5 minutes to obtain the bioactive components that exhibited the antimicrobial activity from medicinal plants.

Similarly, there were significant statistical differences at $(p \leq 0.05)$ level between different parts of fruit. Our results are in agreement with the previous studies where Li et al., (2006) found that the total phenolic content of the peel extract was nearly 10 -fold as high as that of the pulp extract in pomegranate. Further similar result was reported by Tomas-Barberan et al., (2006), who found that peel tissues usually contained larger amount of phenolics than did flesh tissues, in addition to the similar results of the juice that reported by Al Maiman and Ahmad (2002), our findings suggest that pomegranate juice extracts had the lowest total phenolic content in comparison with other fruit parts.

In an other study, Al-Huqail et al., (2018) investigated the antioxidant activity of aqueous ethanolic extracts of $P$. Granatum $\mathrm{L}$. peel and seed coat and $P$. Protopunica seed coat. The findings revealed that the two extracts had considerably different phenolic and total flavonoid levels, as well as distinct phytochemical components. The peel extracts were subjected to Gas Chromatography Mass Spectroscopy (GC-MS) analysis, which showed twentysix components. Benzenepropanoic acid, 1H-pyrrole-2,5-dione, 1,2 benzenedicarboxylic acid, 1-(propylthio)-(CAS) ethanol (CAS) ethylalcohol methyl ester of 3-methoxypropionic and 2-propanol were the most important.

Ozgen et al., (2008), on the other hand, confirm that pomegranate is a fruit rich in phenolic antioxidants, namely anthocyanins, but their concentration differs between types or sub-species. The fruit has a high concentration of flavonoids; it is believed that this class of chemicals accounts for 0.2 percent to 1 percent of the fruit's weight, with the peel accounting for around 30 percent of all anthocyanidins (Akhtar et al., 2015).

Regarding our antibacterial activity results, it is interesting to notice that the nine $S$. aureus tested showed different susceptibility toward the extract tested, which can be possibly explained by the different resistance mechanisms exhibited by each strain. This effect could be attributed to the high concentration of phenolic and flavonoids content in P. granatum extracts. Several studies have appeared in recent years documenting antibacterial effect of flavonoids. Their activity is probably due to their ability to complex with extracellular and soluble proteins and to complex with bacterial cell walls. Lipophilic flavonoids may also disrupt microbial membranes (Al-Maiman and Ahmad 2002). Alves et al. (2013) indicate that the presence of carboxylic acid $(\mathrm{COOH})$, two hydroxyl $(\mathrm{OH})$ groups in para and ortho positions of the benzene ring and also a methoxyl $\left(\mathrm{OCH}_{3}\right)$ group in the meta position in phenolic compound structure seems to play an important role in the studied phenolic compounds anti-MRSA activity. Previous investigations have demonstrated that $P$. granatum seed extract had not the ability to inhibit the activity of Escherichia coli, Klebsiella pneumoniae, Proteus vulgaris, and Salmonella typhi (Gram-negative) microorganisms (Rathinamoorthy et al., 2011), but our study showed an opposite result against the Gram-negative strains as shown in (Table 6). It was interesting to note that the most remarkable and maximum values were illustrious for ethanolic and acetonic peel extracts against Leclercia adecarboxylata, Proteus vulgaris, Citrobacter diversus, and Escherichia coli (E. coli) with inhibition zones higher than $26 \mathrm{~mm}$ and MIC value < to $32 \mu \mathrm{g} / \mathrm{mL}$. These results are in total agreement with other studies, such as the Tunisian variety of P.granatum (Hayouni et al., 2011), the Iraqi variety (Taha Mahmood et al., 2010; Ahmed, 2016) and the Indian variety (Barathikannan $\boldsymbol{e t}$ al., 2016). Our MICs value are higher than those reported by Gullon et al., (2016) for Egyptian variety, MICs values obtained in this study were between 20 and $50 \mathrm{mg} / \mathrm{mL}$ ). In fact, the inhibition zones produced by $P$. granatum extracts were more or less comparable to the pure antibiotic compounds taken as positive drug controls, albeit at lesser concentrations (Fig. 3). Thus, the antimicrobial efficacy of extract could be positively correlated with their respective phenolic and flavonoid contents (Cowan, 1999; Kumar, 2018; Chen et al., 2020).

Regarding the effect of different seed extracts, there is a difference between the results obtained previously against $S$. aureus and the Gram negative strains (AlZoreky, 2009; Gözlekçi et al., 2011; Chen et al., 2020), the ethanolic, acetonic and petroleum extracts of seed have a moderate effect. A recent study, Chen $\boldsymbol{e t}$ al., (2020) confirmed that $S$. aureus is more sensitive than E. coli to pomegranate extract.

The MICs were obtained for extract concentrations ranging from 8 to $512 \mu \mathrm{g} / \mathrm{mL}$. In this study, MICs values less than $512 \mu \mathrm{g} / \mathrm{mL}$ were considered as active for crude extracts. In accordance with the findings reported by Opara et al. (2009) on peels of pomegranates grown in Oman, all peel extracts of the investigated fruit cultivars showed a potent antimicrobial activity against the Gram-negative and Gram-positive bacteria used in the experiment. These findings are opposing to the results of Kanatt $\boldsymbol{e t}$ al. (2010), which reported that pomegranate extracts showed little or no effect against Gram-negative bacteria. It should be noted that the disparities in the findings presented by different researchers may be due to the use of isolates with multiple resistance characteristics, but also to different 
methods used, such as various solvents for chemical solution preparation or various methods for determining MICs.

Previous research has demonstrated that Gram-positive bacteria are more vulnerable because they have only an outer peptidoglycans layer, which is not an effective permeability barrier (Nostro et al., 2000; Al-Zoreky et al., 2009; Chen et al., 2020). However, in the current study, opposing results were found. $S$. aureus (Gram-positive bacteria) has developed resistance to the $\beta$-lactam antibiotics that can be due to the production of chromosomal or plasmid mediated $\beta$-lactamases or by producing PBPs.

Phytochemical screenings of the ethanolic and acetonic peel extracts yield positive results for tannin, flavonoids, alkaloids, phenols, and glycosides. The large group of bioactive compound of $P$. granatum L. extract was also identified, classified as elligitannins (Gosset-Erard $\boldsymbol{e t}$ al., 2021). Their activity is perhaps due to their ability to precipitate proteins, therefore causing leakage of cell membrane of the microorganism, and causing cell lysis, which ultimately leads to cell death. By changing the permeability of microbial cell membranes, phenolic chemicals promote the leaking of molecules such as ribose and Na glutamate. They may also affect membrane activities such as electron transfer, nutrition, enzymatic activities, protein and nucleic acid production, and interaction with membrane proteins, creating morphological and chemical disruption (Tiwari $\boldsymbol{e}$ al., 2009; Kovaevi et al., 2021)

\section{CONCLUSION}

It can be concluded that Algerian pomegranate extracts have respectable antibacterial activities against both of environmental and clinical isolates of $\beta$ lactamase producing MRSA and ESBL-producing Enterobacteriaceae. More importantly, the results indicated that methanolic and acetonic extracts of pomegranate are more effective against bacteria than the petroleum ether extracts. The presence of phytochemical compounds in such quantities in Algerian pomegranate extracts, especially polyphenols, tannins and flavonoids which found in large amounts, may be accountable for antimicrobial activities. Antibacterial activity of $P$. granatum against pathogenic bacteria could provide an alternative promised natural antibacterial treatment without side effects Further investigations should be done to confirm antimicrobial effects of pomegranate against pathogenic bacteria from different sources, and to the bioactive compound that related to these effects and other beneficial activities.

Acknowledgments: This study was supported by the Algerian Ministry of Higher Education and Scientific Research.

\section{REFERENCES}

Agu, G. C., Thomas, B. T., Ogunkomaya, A. M., \& Umeh, S. O. (2020). Betalactamase producing Staphylococcus aureus isolated from some meat and meat-based foods. African Journal of Science and Nature, 7 , 66. https://doi.org/10.46881/ajsn.v7i0.158

Ahmed H. M. (2016). Ethnopharmacobotanical study on the medicinal plants used by herbalists in Sulaymaniyah Province, Kurdistan, Iraq. Journal of ethnobiology and ethnomedicine, 12, 8. https://doi.org/10.1186/s13002-0160081-3

Akhtar, S., Ismail, T., Fraternale, D., \& Sestili, P. (2015). Pomegranate peel and peel extracts: Chemistry and food features. Food Chemistry, 174, 417 425.https://doi.org/10.1016/j.foodchem.2014.11.035

Al-Huqail, A. A., Elgaaly, G. A., \& Ibrahim, M. M. (2018). Identification of bioactive phytochemical from two Punica species using GC-MS and estimation of antioxidant activity of seed extracts. Saudi Journal of Biological Sciences, 25(7), 1420-1428. https://doi.org/10.1016/j.sjbs.2015.11.009

Al-Maiman, S. A., \& Ahmad, D. (2002). Changes in physical and chemical properties during pomegranate (Punica granatum L.) fruit maturation. Food Chemistry, 76(4), 437-441. https://doi.org/10.1016/s0308-8146(01)00301-6

Alves, M. J., Ferreira, I. C. F. R., Froufe, H. J. C., Abreu, R. M. V., Martins, A., \& Pintado, M. (2013). Antimicrobial activity of phenolic compounds identified in wild mushrooms, SAR analysis and docking studies. Journal of Applied Microbiology, 115(2), 346-357.

https://doi.org/10.1111/jam.12196

Al-Zoreky, N. S. (2009). Antimicrobial activity of pomegranate (Punica granatum L.) fruit peels. International Journal of Food Microbiology, 134(3), 244-248.https://doi.org/10.1016/j.ijfoodmicro.2009.07.002

Amararatne, D., Weerakkody, W., \& Jayakody, J. (2012). Bioactive Properties of Fruit Juice of Pomegranate (Punica granatum) Grown in Dry Regions of Sri Lanka. Tropical Agricultural Research, 23(4), 370. https://doi.org/10.4038/tar.v23i4.4873

Aslam, B., Wang, W., Arshad, M. I., Khurshid, M., Muzammil, S., Rasool, M H., Nisar, M. A., Alvi, R. F., Aslam, M. A., Qamar, M. U., Salamat, M., \& Baloch, Z. (2018). Antibiotic resistance: a rundown of a global crisis. Infection and drug resistance, 11, 1645-1658. https://doi.org/10.2147/IDR.S173867

Barathikannan, K., Venkatadri, B., Khusro, A., Al-Dhabi, N. A., Agastian, P., Arasu, M. V., ... Kim, Y. O. (2016). Chemical analysis of Punica granatum fruit peel and its in vitro and in vivo biological properties. BMC Complementary and
Alternative Medicine, 16(1). https://doi.org/10.1186/s12906-016-1237-3

Benguiar,R., Yahla, I., Benaraba, R., Bouamar, S., \& Riazi, A. (2020). Phytochemical analysis, antibacterial and antioxidant activities of pomegranate (Punica granatum L.) peel extracts. International Network for Natural Sciences, 16(6), 35-44. https://doi.org/10.12692/ijb/16.6.35-44

Bush K. (2018). Past and Present Perspectives on $\beta$-Lactamases. Antimicrobial agents and chemotherapy, 62(10), e01076-18 https://doi.org/10.1128/AAC.01076-18

Bush, K., \& Jacoby, G. A. (2010). Updated Functional Classification of $\beta$ Lactamases. Antimicrobial Agents and Chemotherapy, 54(3), 969-976. https://doi.org/10.1128/AAC.01009-09

Chen, J., Liao, C., Ouyang, X., Kahramanoğlu, I., Gan, Y., \& Li, M. (2020). Antimicrobial Activity of Pomegranate Peel and Its Applications on Food Preservation. Journal of Food Quality, 2020, 1-8. https://doi.org/10.1155/2020/8850339

CLSI (Clinical and Laboratory Standards Institute). (2017). Performance Standards for Antimicrobial Susceptibility Testing; $27^{\text {th }}$ ed. Wayne, PA.

Cowan, M. M. (1999). Plant Products as Antimicrobial Agents. Clinical Microbiology Reviews, 12(4), 564-582. https://doi.org/10.1128/cmr.12.4.564 Da Costa, T., de Oliveira, C., Chambers, H., \& Chatterjee, S. (2018). PBP4: A New Perspective on Staphylococcus aureus $\beta$-Lactam Resistance. Microorganisms, 6(3), 57. https://doi.org/10.3390/microorganisms6030057

Debib, A., \& Boukhatem, M. N. (2017). Phenolic Content, Antioxidant and Antimicrobial Activities of "Chemlali" Olive Leaf (Olea europaea L.) Extracts International Journal of Pharmacology, Phytochemistry and Ethnomedicine, 6 , 38-46. https://doi.org/10.18052/www.scipress.com/ijppe.6.38.

Debib, A., Tir-Touil, A., Mothana, R. A., Meddah, B., \& Sonnet, P. (2014). Phenolic Content, Antioxidant and Antimicrobial Activities of Two Fruit Varieties of Algerian Ficus carica L. Journal of Food Biochemistry, 38(2), 207 215. https://doi.org/10.1111/jfbc.12039

Duda-Chodak, A., Tarko, T., Satora, P., \& Sroka, P. (2015). Interaction of dietary compounds, especially polyphenols, with the intestinal microbiota: a review. European journal of nutrition, 54(3),

341.https://doi.org/10.1007/s00394-015-0852-y

Evans, W. C., \& Evans, D. (2009). The scope and practice of pharmacognosy. Trease and Evans' Pharmacognosy, 5-7. https://doi.org/10.1016/b978-0-70202933-2.00002-2

Foster, T. J. (2017). Antibiotic resistance in Staphylococcus aureus. Current status and future prospects. FEMS Microbiology Reviews, 41(3), 430-449 , https://doi.org/10.1093/femsre/fux007

Gosset-Erard, C., Zhao, M., Lordel-Madeleine, S., \& Ennahar, S. (2021) Identification of punicalagin as the bioactive compound behind the antimicrobial activity of pomegranate (Punica granatum L.) peels. Food Chemistry, 352, 129396. https://doi.org/10.1016/j.foodchem.2021.129396

Gözlekçi, S., Saraçoglu, O., Onursal, E., \& Özgen, M. (2011). Total phenolic distribution of juice, peel, and seed extracts of four pomegranate cultivars Pharmacognosy Magazine, 7(26), 161. https://doi.org/10.4103/0973-1296.80681 Guerrero-Solano, J. A., Jaramillo-Morales, O. A., Jiménez-Cabrera, T., UrrutiaHernández, T. A., Chehue-Romero, A., Olvera-Hernández, E. G., \& Bautista, M (2020). Punica protopunica Balf., the Forgotten Sister of the Common Pomegranate (Punica granatum L.): Features and Medicinal Properties-A Review. Plants, 9(9), 1214. https://doi.org/10.3390/plants9091214

Guessaibia, N., Debib, A., Tir-Touil, A., Meddah, B., Saidi, F. \& Benrima A. (2019). Antibacterial activity of Algerian sun-dried raisins extracts against isolates of extended-spectrum beta-lactamase esblproducing enterobacteriaceae. Revue Agrobiologia, 9(1), 1207-1213.

Gullon, B., Pintado, M. E., Pérez-Álvarez, J. A., \& Viuda-Martos, M. (2016) Assessment of polyphenolic profile and antibacterial activity of pomegranate peel (Punica granatum) flour obtained from co-product of juice extraction. Food Control, 59, 94-98.

https://doi.org/10.1016/j.foodcont.2015.05.025

Kanatt, S. R., Chander, R., \& Sharma, A. (2010). Antioxidant and antimicrobial activity of pomegranate peel extract improves the shelf life of chicken products. International Journal of Food Science \& Technology, 45(2), 216 222. https://doi.org/10.1111/j.1365-2621.2009.02124.x

Kliebe, C., Nies, B. A., Meyer, J. F., Tolxdorff-Neutzling, R. M., \& Wiedemann, B. (1985). Evolution of plasmid-coded resistance to broad-spectrum cephalosporins. Antimicrobial Agents and Chemotherapy, 28(2), 302 307. https://doi.org/10.1128/aac.28.2.302

Kovačević, Z., Radinović, M., Čabarkapa, I., Kladar, N., \& Božin, B. (2021) Natural Agents against Bovine Mastitis Pathogens. Antibiotics (Basel, Switzerland), 10(2), 205. https://doi.org/10.3390/antibiotics10020205

Kumar, K. (2020). POMEGRANATE (Punica granatum)(Punica granatum) (n.d.). Westcott's Plant Disease Handbook, 1032-1032.

https://doi.org/10.1007/978-1-4020-4585-1_2421

Li, Y., Guo, C., Yang, J., Wei, J., Xu, J., \& Cheng, S. (2006). Evaluation of antioxidant properties of pomegranate peel extract in comparison with pomegranate pulp extract. Food Chemistry, 96(2), 254260. https://doi.org/10.1016/j.foodchem.2005.02.033

Makarewicz, M., Drożdż, I., Tarko, T., \& Duda-Chodak, A. (2021). The 
Interactions between Polyphenols and Microorganisms, Especially Gut

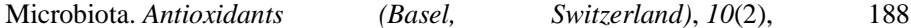
https://doi.org/10.3390/antiox 10020188

Nathan, C., \& Cars, O. (2014). Antibiotic Resistance - Problems, Progress, and Prospects. New England Journal of Medicine, 371(19), 1761-1763. https://doi.org/10.1056/nejmp1408040

Nostro, A., Germano, M. P., D’Angelo, V., Marino, A., \& Cannatelli, M. A. (2000). Extraction methods and bioautography for evaluation of medicinal plant antimicrobial activity. Letters in Applied Microbiology, 30(5), 379384. https://doi.org/10.1046/j.1472-765x.2000.00731.x

Opara, L. U., Al-Ani, M. R., \& Al-Shuaibi, Y. S. (2008). Physico-chemica Properties, Vitamin C Content, and Antimicrobial Properties of Pomegranate Fruit (Punica granatum L.). Food and Bioprocess Technology, 2(3), 315321. https://doi.org/10.1007/s11947-008-0095-5

Ozgen, M., Durgaç, C., Serçe, S., \& Kaya, C. (2008). Chemical and antioxidant properties of pomegranate cultivars grown in the Mediterranean region of Turkey. Food Chemistry, 111(3), 703706. https://doi.org/10.1016/j.foodchem.2008.04.043

Paterson. (1999). Phytochemical Methods. A Guide to Modern Techniques of Plant Analysis. . J. B. Harborne. 15 x 23.4 cm, 302 pp. London: Chapman \& Hall, 1988. Price f79. ISBN 0-412-57260 (hardback). Plant Pathology, 48(1), 146-146. https://doi.org/10.1046/j.1365-3059.1999.00318.x

Rathinamoorthy, R., \& Thilagavathi, G. (2019). Statistical Optimization of Terminalia chebula Fruit Extraction for Improved Antibacterial Activity Against Odour-Causing Bacteria. Proceedings of the National Academy of Sciences, India Section B: Biological Sciences, 90(2), 365374.https://doi.org/10.1007/s40011-019-01105-w

Rawat, D., \& Nair, D. (2010). Extended-spectrum ß-lactamases in gram negative bacteria. Journal of Global Infectious Diseases, 2(3), 263-274 https://doi.org/10.4103/0974-777X.68531

Ray, A. B., \& Bala, K. (2019). Bioactive Compounds and Health Benefits of Phalsa: An Underutilized Fruit. Food Bioactives, 109-128. https://doi.org/10.1201/9780429242793-5.

Sahnouni F, Debib A, Saim S, Bouhadi D, Menadi S. (2021). Phytochemical Content, Antioxidant and Antibacterial Activities of Three Red Macroalgae from Algerian West Coast. (2021). Tropical Journal of Natural Product Research, 5(2), 336-341. https://doi.org/10.26538/tjnpr/v5i2.21

Sh. Ergasheva, F., Kh. Kushiev, K., D. Matchanov, A., J. Ishimov, U., S Shunkor, K., \& Mamirjon, P. K. (2019). Identification of Chemical Content of Fruit and Peel's Extract of Some Varieties' of Pomegranate (Punica granatum L.). International Journal of Current Microbiology and Applied Sciences, 8(05), 734-742. https://doi.org/10.20546/ijcmas.2019.805.086

Sharayei, P., Azarpazhooh, E., Zomorodi, S., \& Ramaswamy, H. S. (2019) Ultrasound assisted extraction of bioactive compounds from pomegranate (Punica granatum L.) peel. LWT, 101, 342-350. https://doi.org/10.1016/j.1wt.2018.11.031

Sharayei, P., Azarpazhooh, E., Zomorodi, S., \& Ramaswamy, H. S. (2019) Ultrasound assisted extraction of bioactive compounds from pomegranate (Punica granatum L.) peel. LWT, 101, 342-350 https://doi.org/10.1111/jfpp.13677

Singleton, V. L., Orthofer, R., \& Lamuela-Raventós, R. M. (1999). [14] Analysis of total phenols and other oxidation substrates and antioxidants by means of folin-ciocalteu reagent. Methods in Enzymology, 152178. https://doi.org/10.1016/s0076-6879(99)99017-1

Sisirak, M., Zvizdic, A., \& Hukic, M. (2010). Methicillin-resistant Staphylococcus aureus (MRSA) as a cause of nosocomial wound infections. Bosnian journal of basic medical sciences, 10(1), 32-37. https://doi.org/10.17305/bjbms.2010.2733

Taha Mahmood, M., J. Mohammed, M., \& Abbas Al-Bayati, F. (2010). Isolation and Identification of Antibacterial Compound from Punica granatum L. Fruit Peels Grown in Iraq. Journal of Education and Science, 23(4), 8089. https://doi.org/10.33899/edusj.2010.59247

Thongson, C., Davidson, P. M., Mahakarnchanakul, W., \& Weiss, J. (2004) Antimicrobial activity of ultrasound-assisted solvent-extracted spices. Letters in Applied Microbiology, 39(5), 401-406. https://doi.org/10.1111/j.1472765x.2004.01605.X

Titilawo, Y., Obi, L., \& Okoh, A. (2015). Antimicrobial resistance determinants of Escherichia coli isolates recovered from some rivers in Osun State, SouthWestern Nigeria: Implications for public health. Science of The Total Environment, 523, 82-94. https://doi.org/10.1016/j.scitotenv.2015.03.095

Tiwari, B. K., Valdramidis, V. P., Bourke, P., \& Cullen, P. (n.d.). Application of plant-based antimicrobials in food preservation. Natural Antimicrobials in Food Safety and Quality, 204-223.https://doi.org/10.1079/9781845937690.0204

Tomás-Barberán, F. A., \& Espín, J. C. (2001). Phenolic compounds and related enzymes as determinants of quality in fruits and vegetables. Journal of the Science of Food and Agriculture, 81(9), 853876. https://doi.org/10.1002/jsfa. 885

van den Honert, M. S., Gouws, P. A., \& Hoffman, L. C. (2021). A Preliminary Study: Antibiotic Resistance of Escherichia coli and Staphylococcus aureus from the Meat and Feces of Various South African Wildlife Species. Food science of animal resources, 41(1), 135-144. https://doi.org/10.5851/kosfa.2020.e62 Witkamp, R. F., \& van Norren, K. (2018). Let thy food be thy medicine.... when possible. European Journal of Pharmacology, 836, 102-114. https://doi.org/10.1016/j.ejphar.2018.06.026 